\title{
Incidence of skin conditions in neonates born at a public hospital associated with some variables in pregnant women at risk
}

\author{
Incidência de dermatoses em neonatos de enfermaria para gestantes de risco em hospital público
}

\author{
José Roberto Paes de Almeida ${ }^{1}$, Mauricio Mota de Avelar Alchorne ${ }^{2}$, Mauro Abrahão Rozman ${ }^{3}$
}

\begin{abstract}
Objectives: To verify the incidence of skin diseases in newborns of pregnant women at risk of a public hospital in the city of Santos, Brazil (Hospital Guilherme Alvaro), determining the potential relation between these dermatoses and diseases presented by the mothers. Methods: A total of 1,000 neonates were examined in the first 36 hours of life. The examination was repeated daily in each child up to hospital discharge. The paternal and newborn variables were submitted to analysis to detect statistically significant associations. Results: The most frequent skin disorders were: Mongolian spot $(69.8 \%)$, erythema toxicum neonatorum $(19.7 \%)$, Port-wine stain (angiomatous naevi) (13.9\%), and hypertrichosis lanuginose (10.3\%). Conclusions: Minipuberty had a low incidence in neonates of diabetic mothers. The incidence of Mongolian spot was very low among newborns classified as caucasian.
\end{abstract}

Keywords: Statistical analysis; Congenital abnormalities; Skin diseases/epidemiology; Infant, newborn

\section{RESUMO}

Objetivos: 0 principal objetivo deste trabalho foi estudar as dermatoses em uma população específica de recém-nascidos do Hospital Guilherme Álvaro (Santos, SP), verificando-se a possível correlação dessas dermatoses com doenças apresentadas pelas mães durante a gestação. Métodos: Mil crianças recém-nascidas foram examinadas nas primeiras 36 horas de vida e reexaminadas todos os dias seguintes, até a alta hospitalar. As variáveis paternas e as dos recém-nascidos foram submetidas à análise para se detectarem relações significativas estatisticamente. Resultados: As dermatoses mais diagnosticadas foram: mancha mongólica $(69,8 \%)$, eritema tóxico neonatal $(19,7 \%)$, mancha de vinho-do-porto $(13,8 \%)$ e hipertricose lanuginosa (10,3\%). Conclusões: A puberdade em miniatura teve baixa incidência entre os neonatos de mães diabéticas. A mancha mongólica teve incidência muito baixa entre recém-nascidos classificados como brancos.

Descritores: Análise estatística; Anormalidades congênitas; Dermatopatias/epidemiologia; Recém-nascido

\section{INTRODUCTION}

As early as in 1895, Ballantyne, an obstetrician from Edinburgh, evaluated dermatoses in neonates and published a monograph entitled "Fetal diseases and deformities" (apud Nanda et al.)(1). In 1953, Pratt published an $\operatorname{article}^{(2)}$ that was followed by 26 papers, the last published by Moosavi, in Iran, 2006 ${ }^{(3)}$. In Brazil, these studies were performed by Nascimento, in 1992, in Rio de Janeiro $^{(4)}$, and by Pereira, in 1997, in Belo Horizonte ${ }^{(5)}$.

In a very peculiar way, the population seen at Hospital Guilherme Álvaro is composed of low-income individuals with poor social and financial status, coming from different towns in the coastal area around the city of Santos. It should also be emphasized that the target population for this hospital comprises risk pregnant women. Risk pregnancy is understood as the emergence, during pregnancy, of one or more of the following conditions: anemia, poor prenatal follow-up, low weight gain, excessive weight gain, smoking habit, alcohol abuse, hypertension, diabetes, collagen diseases, multiple pregnancy, hemorrhages, restricted intrauterine growth, early rupture of membranes, ovular infection and maternal-fetal blood incompatibility. Several other lists can be found in the literature; however, it is necessary to select the risk factors according to the studied population $^{(6)}$.

\footnotetext{
Study carried out at Hospital Guilherme Alvaro, Santos (SP), Brazil; and Universidade Federal de São Paulo - UNIFESP, São Paulo (SP), Brazil.

1 Master's degree in Health Sciences; Assistant professor at Centro Universitário Lusíada - UNILUS, Santos (SP), Brazil.

${ }^{2}$ Full professor of Dermatology at Escola Paulista de Medicina of Universidade Federal de São Paulo - UNIFESP, São Paulo (SP), Brazil.

${ }^{3}$ Lecturer of Epidemiology at Universidade Católica de Santos - UNISANTOS, Santos (SP), Brazil.

Corresponding author: José Roberto Paes de Almeida - Avenida Dr. Bernardino de Campos, 649, apto 91 - Campo Grande - CEP 11065-003 - Santos (SP), Brazil - Tel.: $3234-2416$ - e-mail: jrpaesalmeida@globo.com

Received on Sep 18, 2009 - Accepted on Apr 12, 2010

The authors declared there is no conflict of interest.
} 


\section{OBJECTIVE}

To verify the incidence of dermatoses in the first days of life as well as the potential influence of variables related to mothers and newborns in the onset of these abnormalities.

\section{METHODS}

The study was initiated on December 27, 2000, with consecutive examination of all newborns until completing a total of one thousand neonates, which occurred on July 30, 2001. The inclusion criterion was all neonates born in the established period of time and the exclusion criterion was the presence of any illness keeping the neonate immobilized at the Intensive Care Unit (ICU), thus preventing a daily appropriate dermatological examination. The study was approved by the Research Ethics Committees of Hospital Guilherme Álvaro (approval date: April 22, 2002) and UNIFESP (CEP 1204/06).

Newborns were first examined within the first 36 hours of life and the examination was repeated every day while they were at hospital, with the purpose of diagnosing dermatoses that might appear after the child had already been examined. Some children were discharged on the second or third day of life and the examinations were limited to those days. Dermatological exams were performed in fully undressed neonates, in a well-lit room and after the newborn had been bathed for removal of the vernix caseosa. All examinations were performed by a single researcher.

Information about the newborns and their parents was collected to evaluate the potential association of the risk factors chosen and the emergence of dermatological diseases. The mothers answered a structured questionnaire about the following variables: parents' skin color and age and consanguinity between parents; as to the mother only, the following variables were searched: place of origin, smoking habit, alcohol use, drug use, HIV status, treatments received for diseases diagnosed during pregnancy, number of pregnancies, occurrence of miscarriages and stillborns in previous pregnancies.

The variables studied in the newborns included: sex, skin color, weight, length, blood type, RH factor, 1-minute Apgar score, 5-minute Apgar score and weight for gestational age.

Some variables, such as skin color of father, mother and newborn were grouped as Non-White and White, with the latter being considered as risk exposure. Female sex was considered to be risk exposure.

The quantitative variables were grouped to allow more efficiency in the statistical analysis: 1-minute
Apgar score was grouped as 0-7 and 8-10, with this second stratum considered as exposure. The 5-minute Apgar score was grouped as 0-9 and 9-10, with this second stratum considered as exposure.

The other quantitative variables studied were grouped as follows: mother's age: younger than 20, 20 to 29,30 or more years old; father's age: younger than 25 , 25 to 34 and 35 or more years old; number of children alive: $0,1,2,3$ and 4 or more; previous pregnancies: 0 , $1,2,3$ and 4 or more; birth weight: $<2,500 \mathrm{~g}, 2,500$ to $3,499 \mathrm{~g}$ and $3,500 \mathrm{~g}$ or more; length: $<45 \mathrm{~cm}, 45$ to 49 $\mathrm{cm}$ and $50 \mathrm{~cm}$ or more; weight for gestational age: SGA, AGA and LAG, according to the literature; gestational age: up to 36 weeks, 36.1 to 40 weeks, more than 40 weeks.

To evaluate the association of the variables studied and the occurrence of skin lesions, Odds Ratio (OR) was calculated with a $95 \%$ confidence interval in the univariate analysis.

The variables showing a statistically significant association in the univariate analysis and those that, in this analysis, showed association with $p<0.3$ were included in the multivariate analysis, carried out by non-conditional logistic regression, defining the factors independently associated to skin diseases.

\section{RESULTS}

The number of pregnant women who did not have any risk was $684(68.4 \%)$. Out of the 316 women considered to have risk pregnancy, the following conditions were detected: smoking habit in 164 (51.9\%), high blood pressure in $66(14.9 \%)$, diabetes in $47(14.9 \%)$, high blood pressure associated with diabetes in $16(5.1 \%)$, HIV positive test in $17(5.4 \%)$ and drug use in 6 $(1.9 \%)$.

Approximately $87.9 \%$ of newborns presented one or more skin diseases and $12.1 \%$ did not show any skin involvement. Table 1 shows the diagnoses with the respective frequency and percentages found.

The skin abnormalities presenting any significant result in the statistical analysis included Mongolian spot, erythema toxicum neonatorum, port-wine stain, sebaceous gland hyperplasia, physiological desquamation, minipuberty, congenital melanocytic nevus and forceps-related ecchymosis.

In regard to the Mongolian spot in the univariate analysis, the variables that were statistically associated with its presence were the father's skin color $(\mathrm{OR}=$ $0.49 ; 95 \%$ CI $[0.37-0.66])$, mother's skin color $(\mathrm{OR}=$ $0.15 ; 95 \%$ CI [ $0.09-0.23])$, newborn's skin color $(\mathrm{OR}=$ $0.03 ; 95 \%$ CI [0.01 - 0.07]) and birth weight ( $\chi^{2}$ test for trend $=7.4 ; p=0.006)$. Although they did not show a statistically significant association with the Mongolian 
Table 1. Frequency and percentage of diagnoses

\begin{tabular}{|c|c|c|}
\hline Clinical diagnoses & Frequency & $(\%)$ \\
\hline Mongolian spot & 698 & 69.8 \\
\hline Erythema toxicum neonatorum & 197 & 19.7 \\
\hline Port-wine stain & 138 & 13.8 \\
\hline Physiological jaundice & 118 & 11.8 \\
\hline Hypertrichosis lanuginosa & 103 & 1.03 \\
\hline Sebaceous gland hyperplasia & 78 & 7.8 \\
\hline Physiological desquamation & 70 & 7.0 \\
\hline Minipuberty & 41 & 4.1 \\
\hline Cutis marmorata & 22 & 2.2 \\
\hline Café-au-lait stain & 20 & 2.0 \\
\hline Pigmented nevus & 20 & 2.0 \\
\hline Milium & 17 & 1.7 \\
\hline Congenital clubfoot & 8 & 0.8 \\
\hline Chemical conjunctivitis & 7 & 0.7 \\
\hline Transient neonatal pustular melanosis & 6 & 0.6 \\
\hline Forceps-related ecchymosis & 4 & 0.4 \\
\hline Hyperpigmentation (silver nitrate) & 4 & 0.4 \\
\hline Miliaria & 4 & 0.4 \\
\hline Polydactyly & 3 & 0.3 \\
\hline Meningocele & 2 & 0.2 \\
\hline Trisomy 21 & 2 & 0.2 \\
\hline Sacral sulcus & 2 & 0.2 \\
\hline Cleft lip & 2 & 0.2 \\
\hline Suction blister & 2 & 0.2 \\
\hline Accessory tragus & 2 & 0.2 \\
\hline Oral candidiasis & 1 & 0.1 \\
\hline Hydrocephalus & 1 & 0.1 \\
\hline Congenital leukemia cutis & 1 & 0.1 \\
\hline Achromic nevus & 1 & 0.1 \\
\hline Sebaceous nevus & 1 & 0.1 \\
\hline Rh isoimmunization & 1 & 0.1 \\
\hline
\end{tabular}

spot for a significance level of $95 \%$, variables such as length, weight for gestational age and blood type showed an association with $p<0.3$ and were tested in the multivariate model. The multivariate analysis showed that the newborn skin color is the only variable showing an independent association with the Mongolian spot for a significance level of $95 \%$.

Concerning erythema toxicum neonatorum, the variables presenting a statistically significant association in the univariate analysis were: neonate sex $(\mathrm{OR}=$ 0.63 ; 95\% CI [0.45 - 0.88]), birth weight ( $\chi^{2}$ test for trend $=23.8 ; \mathrm{p}<0.001)$, length $\left(\chi^{2}\right.$ test for trend $=$ $6.2 ; \mathrm{p}=0.013)$, weight for gestational age $\left(\chi^{2}\right.$ test for trend $=13.6 ; \mathrm{p}<0.001)$, gestational age $\left(\chi^{2}\right.$ test for trend $=4.9 ; \mathrm{p}=0.026)$. Although they did not show a statistically significant association with erythema toxicum neonatorum for a significance level of $95 \%$, variables such as 1-minute Apgar score and blood type showed an association with $\mathrm{p}<0.3$ and were tested in a multivariate model. The multivariate analysis showed that the variables independently associated with erythema toxicum neonatorum were: $\operatorname{sex}(\mathrm{OR}=0.70$; 95\% CI [0,51 - 0,97]) and 1-minute Apgar score (OR = $1.56 ; 95 \% \mathrm{CI}[0.99-2.46])$ and birth weight ( $\chi^{2}$ test for trend $=19.8 ; \mathrm{p}<0.001)$. The higher the weight, the higher the likelihood of presenting the disease.

In regard to the port-wine stains, the variables that showed statistically significant association in the univariate analysis were: mother with high blood pressure $(\mathrm{OR}=0.52 ; 95 \% \mathrm{CI}[0.27-0.95])$, birth weight $\left(\chi^{2}\right.$ test for trend $\left.=6.4 ; \mathrm{p}<0.012\right)$, length $\left(\chi^{2}\right.$ test for trend $=5.8 ; \mathrm{p}<0.016)$ and $\operatorname{sex}(\mathrm{OR}=1.47 ; 95 \% \mathrm{CI}$ [1.00 - 2.15]). The variables that, although not showing a statistically significant association in the univariate analysis, were tested in the multivariate model for presenting association with $\mathrm{p}<0.3$ were: maternal age, blood type, father's skin color, 1-minute Apgar score and treatment. In the multivariate analysis, the variables independently associated were: $\operatorname{sex}(\mathrm{OR}=1.56 ; 95 \% \mathrm{CI}$ $[1.07-2.25])$, father's skin color $(\mathrm{OR}=1.53 ; 95 \% \mathrm{CI}$ [1.06 - 2.23]) and mother with high blood pressure (OR $=0.52 ; 95 \% \mathrm{CI}[0.29-0.93])$ and length $\left(\chi^{2}\right.$ test for trend $=5.7 ; \mathrm{p}=0.017$ ).

As to sebaceous gland hyperplasia, the variables that showed statistically significant association in the univariate analysis were: father's skin color $(\mathrm{OR}=$ 1.53, 95\%CI: [1.08 - 3.06]) and 1-minute Apgar score $(\mathrm{OR}=0.5495 \% \mathrm{CI}[0.31-0.95])$, being less frequent in children with values $\geq 8$. The variables that did not show a statistically significant association in the univariate analysis, but presented a significance level lower than 0.3 , being, for this reason, included in the multivariate analysis were: maternal age, paternal age, birth weight, length and blood type. In the multivariate analysis, the father's skin color was the only variable that was maintained independently associated to the sebaceous gland hyperplasia.

In physiological desquamation, the variables that showed statistically significant association in the univariate analysis were: 5 -minute Apgar score $(\mathrm{OR}=$ $0.46 ; 95 \% \mathrm{CI}[0.23-0.90])$ and gestational age ( $\chi^{2}$ test for trend $=8.6 ; \mathrm{p}=0.003)$. The higher the gestational age, the higher the likelihood of physiological desquamation. The variables presenting association with $\mathrm{p}<0.3$ and included in the multivariate analysis were as follows: previous pregnancies, drugs, miscarriages, number of children alive, high blood pressure and diabetes mellitus. In the multivariate analysis, gestational age $\left(\chi^{2}\right.$ test for trend $=11.1 ; \mathrm{p}=0.001)$ and 5-minute Apgar score $(\mathrm{OR}=46 ; 95 \% \mathrm{CI}[0.46-0.87])$ were independently associated with the physiological desquamation in the newborn.

In the univariate analysis, minipuberty showed a statistically significant association with the presence of diabetes in the mother $(\mathrm{OR}=0.14,95 \% \mathrm{CI}[0.01$ - 
$0.95])$, sex of neonate $(\mathrm{OR}=2.36,95 \% \mathrm{CI}[1.15$ - 4.89]), maternal age $\left(\chi^{2}\right.$ test for trend $\left.=3.91 ; \mathrm{p}=0.046\right)$ and weight for gestational age $\left(\chi^{2}\right.$ test for trend $=4.35 ; \mathrm{p}$ $=0.037)$. The variables presenting a significance level lower than 0.3 in the univariate analysis and that were also tested in the multivariate analysis were high blood pressure and 1-minute Apgar score. In the multivariate analysis, variables presenting independent association with minipuberty were sex $(\mathrm{OR}=2.21,95 \%$ CI $[1.13$ - 4.36]), diabetes of the mother $(\mathrm{OR}=0.13$; 95\% CI [0.02 - 0.99]) and weight for gestational age $\left(\chi^{2}\right.$ test for trend $=4.0 ; p=0.042)$. Females are more susceptible. Newborns of diabetic mothers are less susceptible and neonates classified as small for gestational age are more frequently affected, while those who are large for gestational age have a lower risk of presenting the abnormality.

In regard to the congenital melanocytic nevus, consanguinity was the only factor that showed a statistically significant association in the univariate analysis $(\mathrm{OR}=21.67,95 \% \mathrm{CI}$ [2.66 - 141.80]). Variables that did not show a statistically significant association in the univariate analysis, but presented a significance level lower than $\mathrm{p}<0.3$ and were tested in the multivariate analysis, were: length and weight for gestational age. Multivariate analysis confirmed that consanguinity is the only factor that shows an independent association with the congenital melanocytic nevus.

The only variable that showed a statistically significant association to the forceps-related ecchymosis in the univariate analysis was maternal age $\left(\chi^{2}\right.$ test for trend $=6.48 ; p=0.011)$. The following variables showed significance level lower than 0.3 and were included in the multivariate analysis: number of children alive, previous pregnancies and paternal age. For the forcepsrelated ecchymosis, the only independently associated variable in the multivariate analysis was maternal age.

The remaining diagnoses, which can be identified in table 1, did not show a significant association from the statistical point of view in any of the variables studied.

\section{DISCUSSION}

As this study aimed to evaluate the occurrence of all dermatological diseases affecting neonates, the necessary sample was estimated to verify the diseases with minimum incidence of $8 \%$, significance level of $95 \%$ and maximum error of $20 \%$ of incidence, which may imply in less precise estimates for less frequent diseases.

To facilitate the multivariate analysis, Odds Ratio (OR) was chosen as the effect measurement. Odds Ratio is not a good index to estimate the relative risk for diseases with higher incidence, as in this study, especially for evaluating the presence of any type of dermatosis and Mongolian spot. Several variables chosen do not enable establishing, according to the existing literature, a causal explanation with biological plausibility for the diseases studied. These variables must be understood as factor markers of a group of causes that are still unknown.

The diagnosis of skin conditions was made during the period when the newborns were hospitalized, varying between two and eight days. It is possible that some late-occurring diseases may have been underestimated in cases of early hospital discharge. Newborns requiring treatment at ICU were excluded. No evaluation of this sample of children was carried out to verify the possibility of selection bias, which, if present, must be minimum, since only six neonates were excluded from the study for this reason.

By comparing our results with the references, we observed some data that are emphasized below.

The methodologies used were very different in the 27 studies examined; one of them can state that there are no two studies in which the methodology and results can be fully compared.

In regard to age, it was verified that Pratt examined the neonates from the $4^{\text {th }}$ to $8^{\text {th }}$ days of life, since his main purpose was to detect the presence of angiomas ${ }^{(2)}$, which frequently occur at a later stage. Four studies did not mention the neonate age ${ }^{(7-10)}$. Two studies examined the neonates up to the $30^{\text {th }}$ day of life, with one initiated in the first hours of life, i.e., 0 days of life ${ }^{(4)}$ and another on the $2^{\text {nd }}$ day of life ${ }^{(11)}$. Four studies examined children younger than seven days old ${ }^{(12-15)}$. Rohr examined neonates who were exactly three-day old ${ }^{(16)}$. An author examined the neonates every day from the $1^{\text {st }}$ to the $4^{\text {th }}$ day of life ${ }^{(17)}$. Twelve authors examined neonates in the first 96 hours of life ${ }^{(5,18-24)}$ and, among these, three studies examined newborns who were younger than 48 hours old ${ }^{(1,25-26)}$, one of them examined newborns up to 48 hours of life, ${ }^{(3)}$ one study comprised newborns with $90 \%$ of children with less than 24 hours of life ${ }^{(27)}$. In one study, the age varied between 1 and 20 days ${ }^{(28)}$.

This great variation in age of newborns at the time of dermatological examination may explain the differences found in the literature regarding frequency of certain skin diseases. When the exam is performed at a later stage, one may miss the chance of diagnosing lesions that spontaneously disappear in a short period of time, such as erythema toxicum neonatorum and the transient neonatal pustular melanosis. When the examination is carried out only in the first hours of life, lesions that appear at a later stage such as angiomas may not be diagnosed. In some studies, the age varied between 0 and 30 days, which compromises quality. 
The number of newborns examined varied greatly in the studies published (Figure 1).

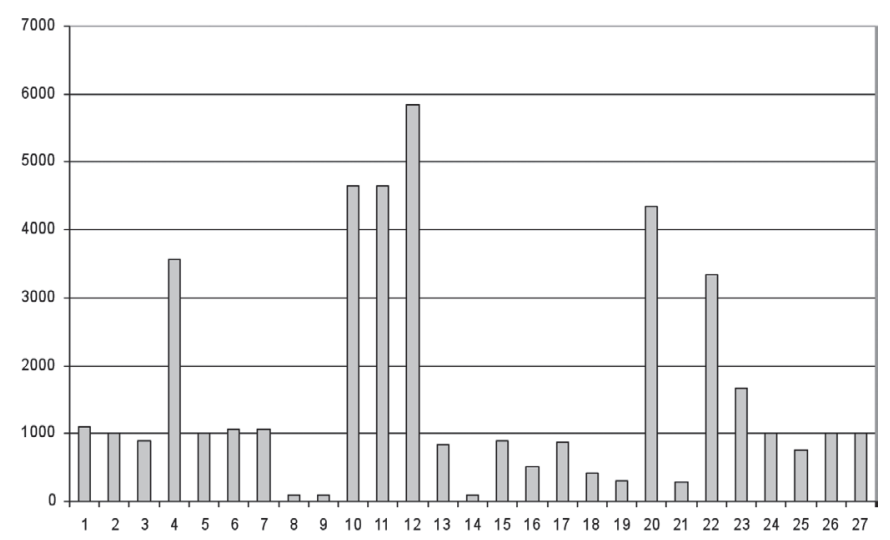

Figure 1. Graph showing distribution of number of neonates in each study published

Six published studies do not mention the children's skin color ${ }^{(3,6,15,16,22,27)}$. Two authors examined only Black children ${ }^{(11,20)}$. Two authors examined only Asian children ${ }^{(9,26)}$. One author examined only White children $^{(14)}$. One author examined Indians and Mestizos $^{(1)}$. The remaining studies examined children of several ethnicities.

As to the purpose of the investigations, itwas observed that Pratt intended to study angiomas and, secondarily, nevi and Mongolian spot ${ }^{(2)}$. Walton was interested in evaluating pigmented lesions ${ }^{(19)}$ and Fox was concerned about pigmented lesions in Black neonates ${ }^{(20)}$. The remaining studies examined dermatoses in general.

For being a public reference hospital in the south coast of the State of São Paulo, pregnant women came from all towns in the coastal area around the city of Santos, from Bertioga to Itanhaém, being the majority from Santos and São Vicente, with the last two cities having almost the same proportion of patients.

The great majority of neonates presented one or more skin abnormalities, which is not much different from figures found in the literature.

Mongolian spot has a statistically significant association to the newborn skin color, is more frequent in non-white neonates, which is already an established fact in the literature. The condition was diagnosed in only five children classified as White; if the father of these neonates had been examined (father's skin color was informed by the mother), the number of White children with Mongolian spot might have been lower. Niedelman stated that he never found Mongolian spots in White children and Epstein calculated the frequency of Mongolian spot among White children as roughly one in 600 , i.e., a frequency of $0.16 \%{ }^{(2)}$; however, in a study involving 4,346 White newborns, there were two neonates with Mongolian spot, accounting for a frequency of $0.04 \%$, but one of these children had a parent classified by the author as gipsy and the other child had both parents classified as gipsy ${ }^{(4)}$.

Erythema toxicum neonatorum is associated with higher newborn weight, as already reported in the literature $^{(5,16)}$. The association with sex and 1-minute Apgar score found in this study does not present bibliographic reference. Males had a higher risk of presenting the lesion, a fact that has not been described in the literature yet.

As to physiological desquamation, the association with gestational age of more than 40 weeks is widely known, but association with 5-minute Apgar score is not; however, there is a reference about the higher frequency in malnourished individuals.

Children of consanguineous parents have a high frequency of congenital melanocytic nevus as compared to the non-consanguineous findings. The literature reports the emergence of this nevus as occasional ${ }^{(28)}$.

\section{CONCLUSIONS}

A total of 31 diagnoses were made in the newborns examined, and four of them were not related to skin lesions. The frequency of $87.9 \%$ of neonates with one or more skin conditions is within the limits found in the literature. The relation between maternal conditions and the presence of dermatoses in newborns was observed in minipuberty. Consanguinity proved to be a risk factor for congenital melanocytic nevus.

\section{REFERENCES}

1. Nanda A, Kaaur S, Bhakoo ON, Dhall K. Survey of cutaneous lesions in Indian newborns. Pediatr Dermatol. 1989;6(1):39-42.

2. Pratt AG. Birhmarks in infants. Arch Dermatol. 1953;67:302-5.

3. Moosavi Z, Hosseini T. One-year survey of cutaneous lesions in 1000 consecutive Iranian newborns. Pediatr Dermatol. 2006;23(1):61-3.

4. Nascimento LV, Rozo EM, Yarak S, Coimbra SD, Porto JA. Prevalência de dermatoses em recém-nascidos no berçário de um hospital universitário. An Bras Dermatol. 1992;67(6):305-7.

5. Pereira JB. Prevalência de dermatoses no recém-nascido: estudo comparativo entre dois hospitais de Belo Horizonte, Brasil [dissertação]. Belo Horizonte: Universidade Federal de Minas Gerais; 1997.

6. Lippi UG. Enfoque de risco. In: Segre CAM. Perinatologia: fundamentos e prática. São Paulo: Sarvier; 2002. p. 55-60.

7. Desmons F, Chevillard Y. Fréquence des diverses dermatoses du nouveau-né et du nourrisson pendant les dix premiers jours de la vie. Bull Soc Fr Dermatol Syphiligr. 1974;81(2):169-258.

8. Dickson J, Yue P. A study of the incidence of neonatal dermatoses. Australas J Dermatol. 1979;20(2):78-81.

9. Hidano A, Purwoko R, Jitsukawa K. Statistical survey of skin changes in Japanese neonates. Pediatr Dermatol. 1986;3(2):140-4.

10. Prada EMG, Sarmiento ME. Manchas congenitas. Rev Soc Boliv Pediatr. 1987;26(3):207-14. 
11. Saraçli T, Kenney JA Jr, Scott RB. Common skin disorders in the newborn negro infant: observations based on the examination of 1.000 babies. $J$ Pediatr. 1963;62:358-62.

12. Rivers JK, Frederiksen PC, Dibdin C. A prevalence survey of dermatoses in the Australian neonate. J Am Acad Dermatol. 1990;23(1):77-81.

13. Prigent $F$, Vige $P$, Martinet $C$. Lésions cutanées au cours de la première semaine de vie chez 306 nouveau-nés consécutifs. Ann Dermatol Venereol. 1991;118:697-9.

14. Karvonen SL, Vaajalahti P, Marenk M, Janas M, Kuokkanen K. Birthmarks in 4346 Finnish newborns. Acta Derm Venereol. 1992;72(1):55-7.

15. Lorenz S, MaierC, Segerer H, LandthalerM, HohenleutnerU. Hautveränderungen bei Neugeborenen in den ersten 5 Lebenstagen. Hautarzt. 2000;51 (6):396400.

16. Rohr JB. The skin of the newborn. Australas J Dermatol. 1975;16(3):118-20.

17. Sezer V, Ovack E, Oran 0 . Common skin disorders in newborn infants. Turk J Pediatr. 1965;7(2):104-11.

18. Jacobs $A H$, Walton RG. The incidence of birthmarks in the neonates. Pediatrics. 1976;58(2):218-22.

19. Walton RG, Jacobs AH, Cox AJ. Pigmented lesions in newborn infants. $\mathrm{Br} J$ Dermatol. 1976;95(4):389-96.
20. Fox JN, Walton RG, Gottlieb B, Castellano A. Pigmented skin lesions in black newborn infants. Cutis. 1979;24(4):399-402.

21. Alper J, Holmes LB, Mihm MC. Birthmarks with serious medical significance: nevocellular nevi, sebaceous nevi, and multiple café au lait spots. J Pediatr. 1979;95(5 Pt 1):696-700.

22. Alper JC, Holmes LB. The incidence and significance of birthmarks in a cohort of 4641 newborns. Pediatr Dermatol. 1983;1(1):58-68.

23. Valle LE, Gomez JL, Rausa PM. Dermatosis en el recien nacido. Rev Arg Dermatol. 1989;70(2):102-11.

24. Kahana M, Feldman M, Abudi Z, Yurman S. The incidence of birthmarks in israeli neonates. Int J Dermatol. 1995;34(10):704-6.

25. Plantin $P$, Le Roy JP, Delaire P, Guillois $B$, Guillet G. Lésions cutanées bénignes observées dans les 48 premières heures de vie chez 874 nouveau-nés d'une maternité de chu. Ann Dermatol Venereol. 1990;117:181-4.

26. Tsai F, Tsai C. Birthmarks and congenital skin lesions in Chinese newborns. J Formos Med Assoc. 1993;92(9):838-41.

27. Osburn K, Schosser RH, Everett MA. Congenital pigmented and vascular lesions in newborn infants. J Am Acad Dermatol.1987;16(4):788-92.

28. Magana-Garcia M, Gonzalez-Campos N. Skin lesion in 1000 newborns. A case and control study. Gac Med Mex. 1997;133(5):407-11. 